Article

\title{
Halogen Interactions in 2,4,5-Tribromoimidazolium Salts
}

\author{
Carmen Froschauer $^{1,2}$, Volker Kahlenberg ${ }^{3}$, Gerhard Laus ${ }^{1, *}$ and Herwig Schottenberger ${ }^{1}$ \\ 1 Faculty of Chemistry and Pharmacy, University of Innsbruck, 6020 Innsbruck, Austria; \\ E-Mails: carmen.froschauer@uibk.ac.at (C.F.); herwig.schottenberger@uibk.ac.at (H.S.) \\ 2 Competence Center of Wood Composites and Wood Chemistry K-Plus, 4021 Linz, Austria \\ 3 Institute of Mineralogy and Petrography, University of Innsbruck, 6020 Innsbruck, Austria; \\ E-Mail: volker.kahlenberg@uibk.ac.at \\ * Author to whom correspondence should be addressed; E-Mail: gerhard.laus@uibk.ac.at; \\ Tel.: +43-512-507-57080; Fax: +43-512-507-57099.
}

Received: 22 May 2012; in revised form: 18 June 2012 / Accepted: 28 June 2012 /

Published: 27 July 2012

\begin{abstract}
The crystal structures of 2,4,5-tribromo-1-(prop-2-ynyl)imidazole and seven new 1,3-dialkyl-2,4,5-tribromoimidazolium salts $\left(R^{1}=\right.$ propenyl, propynyl, dibromopropenyl; $R^{2}=\mathrm{Me}, \mathrm{Et}$ ) with halogen-containing anions (tetrafluoroborate, hexafluorophosphate, triflimide) were determined. The structures revealed halogen $\cdots$ halogen and anion $\cdots \pi$ interactions. Contacts of the type $\mathrm{Br} \cdots \mathrm{Br}, \mathrm{Br} \cdots \mathrm{F}, \mathrm{Br} \cdots \mathrm{O}, \mathrm{Br} \cdots \mathrm{N}, \mathrm{F} \cdots \mathrm{F}, \mathrm{H} \cdots \mathrm{Br}, \mathrm{H} \cdots \mathrm{F}, \mathrm{F} \cdots \pi$ and $\mathrm{O} \cdots \pi$ were identified. Specific interactions were quantified by Hirshfeld surface analysis.
\end{abstract}

Keywords: bromine; fluorine; halogen interaction; Hirshfeld surface analysis; imidazole

\section{Introduction}

2,4,5-Tribromoimidazole [CARN 2034-22-2], first described in 1877 [1], is readily prepared by bromination of imidazole [2-7]. It has been found in nature [8] and is an effective fire-retardant agent [9]. It has been used as starting material for the synthesis of quaternary salts as high-density ionic liquids [10]. Halogenated imidazoles exhibit insecticidal [11], parasiticidal [12], acaricidal [13], and herbicidal [14] activity. Only few crystal structures of partially brominated imidazole [15] and quaternary imidazolium salts [16-18] have been reported. A cobalt complex of 2,4,5-tribromoimidazole has been published [19]. To our knowledge, no other crystal structures of 2,4,5-tribromoimidazole 
derivatives are known to date. Here we present the structures of eight new compounds of this kind. The quaternary salts are intended for application as non-volatile fire retardants. The olefinic substituents allow the preparation of new materials by polymerization.

\section{Results and Discussion}

The synthesis (Figure 1) of the propenyl and propynyl derivatives 1 and 2 was carried out by known methods. The salts 3-6 were prepared by quaternization of 1 and 2 . Compound 7 was obtained by ion metathesis from 4 , and compounds 8 and 9 by bromination of 6 . The choice of fluorine-containing anions such as tetrafluoroborate, hexafluorophosphate, and bis(trifluoromethanesulfonyl)imide ("triflimide") provided an opportunity to study non-covalent hetero-halogen, homo-halogen, hydrogen-halogen, and other interactions. Crystal data and structure refinement details are summarized in Table 1. Charge transfer complexes of halogens and electron-donor molecules have been the subject of the 1970 Nobel Prize lecture by Odd Hassel [20]. Today it is known that halogen atoms can act as electron-acceptors (X-bond donors) and electron donors (X-bond acceptors). Theoretical calculations predicted negative ring and positive end cap domains of halogen atoms due to their polarizability [21], even for fluorine [22]. In fact, hetero halogen-halogen interactions in both directions, i.e., $\mathrm{Cl} \rightarrow \mathrm{F}$ and $\mathrm{F} \rightarrow \mathrm{Cl}$, have been observed recently [22]. As expected, a classic $\mathrm{Br} \cdots \mathrm{N}$ interaction was found in 2 (Table 2). Some typical examples of this interaction, displayed by brominated N-heterocycles, are found in the Cambridge Structural Database (CSD) [23-26].

Figure 1. Synthesis of 2,4,5-tribromoimidazolium salts. Reagents and solvents: $a:\left(\mathrm{CH}_{3}\right)_{3} \mathrm{O}^{+} \mathrm{BF}_{4}{ }^{-} / \mathrm{CH}_{2} \mathrm{Cl}_{2} ; b:\left(\mathrm{C}_{2} \mathrm{H}_{5}\right)_{3} \mathrm{O}^{+} \mathrm{PF}_{6}{ }^{-} / \mathrm{CH}_{2} \mathrm{Cl}_{2} ; c: \mathrm{Li}^{+} \mathrm{Tf}_{2} \mathrm{~N}^{-} / \mathrm{MeOH} ; d: \mathrm{Br}_{2} / \mathrm{CH}_{2} \mathrm{Cl}_{2}$.

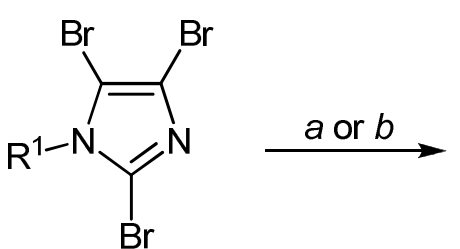

1,2
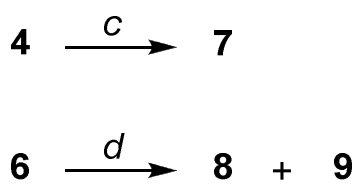<smiles></smiles>

3-6

\begin{tabular}{clll}
\cline { 2 - 4 } $\mathrm{X}^{\ominus}$ & $\mathrm{R}^{1}$ & $\mathrm{R}^{2}$ & $\mathrm{X}$ \\
\cline { 2 - 4 } $\mathbf{1}[31255-41-1]$ & $-\mathrm{CH}_{2}-\mathrm{CH}=\mathrm{CH}_{2}$ & & \\
2 [27442-77-9] & $-\mathrm{CH}_{2}-\mathrm{C} \equiv \mathrm{CH}$ & & \\
$\mathbf{3}$ & $-\mathrm{CH}_{2}-\mathrm{CH}=\mathrm{CH}_{2}$ & $-\mathrm{CH}_{3}$ & $\mathrm{BF}_{4}$ \\
$\mathbf{4}$ & $-\mathrm{CH}_{2}-\mathrm{C} \equiv \mathrm{CH}$ & $-\mathrm{CH}_{3}$ & $\mathrm{BF}_{4}$ \\
$\mathbf{5}$ & $-\mathrm{CH}_{2}-\mathrm{CH}=\mathrm{CH}_{2}$ & $-\mathrm{CH}_{2}-\mathrm{CH}_{3}$ & $\mathrm{PF}_{6}$ \\
6 & $-\mathrm{CH}_{2}-\mathrm{C} \equiv \mathrm{CH}$ & $-\mathrm{CH}_{2}-\mathrm{CH}_{3}$ & $\mathrm{PF}_{6}$ \\
$\mathbf{7}$ & $-\mathrm{CH}_{2}-\mathrm{C} \equiv \mathrm{CH}$ & $-\mathrm{CH}_{3}$ & $\mathrm{Tf}_{2} \mathrm{~N}$ \\
8 & $-\mathrm{CH}_{2}-\mathrm{CBr}=\mathrm{CHBr}$ & $-\mathrm{CH}_{2}-\mathrm{CH}_{3}$ & $\mathrm{PF}_{6}$ \\
9 & $-\mathrm{CH}_{2}-\mathrm{CBr}=\mathrm{CHBr}$ & $-\mathrm{CH}_{2}-\mathrm{CH}_{3}$ & $\mathrm{Br}$ \\
\hline
\end{tabular}

The role of fluorine, which exhibits the lowest polarizability and highest electronegativity of the halogens, in crystal structures of organic compounds has been reviewed [27]. After some controversy, it has been concluded that short $\mathrm{C}-\mathrm{H} \cdots \mathrm{F}$ contacts between oppositely charged molecules are genuine interionic hydrogen bonds [28]. Non-Linear allylic $\mathrm{C}-\mathrm{H} \cdots \mathrm{F}$ interactions [28] were observed in compound 8. Short interactions between covalent halogen atoms ( $\mathrm{Br} \cdots \mathrm{F}$ and $\mathrm{Br} \cdots \mathrm{Br})$ [21] were observed in compounds 3-9. Classic $\mathrm{H}^{-} \mathrm{Br}^{-}$and $\mathrm{Br}^{-\cdots} \mathrm{Br}^{-}$bonds were found in the bromide 9. Similar $\mathrm{Br}^{-\cdots} \mathrm{Br}^{-}$interactions have been observed in the structures of 2-bromoimidazolium bromides [16,18,29-31], a related $\mathrm{Br} \cdots \mathrm{F}$ contact in a 2-bromoimidazolium hexafluorophosphate [30], and a typical $\mathrm{Br} \cdots \mathrm{Br}$ interaction for example in pentabromoferrocene [32]. 
Table 1. Crystal data and structure refinement details.

\begin{tabular}{|c|c|c|c|c|c|c|c|c|}
\hline Compound & 2 & 3 & 4 & 5 & 6 & 7 & 8 & 9 \\
\hline CCDC no. & 881953 & 881952 & 881955 & 881951 & 881954 & 881956 & 881957 & 881958 \\
\hline Chemical formula & $\mathrm{C}_{6} \mathrm{H}_{3} \mathrm{Br}_{3} \mathrm{~N}_{2}$ & $\mathrm{C}_{7} \mathrm{H}_{8} \mathrm{Br}_{3} \mathrm{~N}_{2} \cdot \mathrm{BF}_{4}$ & $\mathrm{C}_{7} \mathrm{H}_{6} \mathrm{Br}_{3} \mathrm{~N}_{2} \cdot \mathrm{BF}_{4}$ & $\mathrm{C}_{8} \mathrm{H}_{10} \mathrm{Br}_{3} \mathrm{~N}_{2} \cdot \mathrm{F}_{6} \mathrm{P}$ & $\mathrm{C}_{8} \mathrm{H}_{8} \mathrm{Br}_{3} \mathrm{~N}_{2} \cdot \mathrm{F}_{6} \mathrm{P}$ & $\mathrm{C}_{7} \mathrm{H}_{6} \mathrm{Br}_{3} \mathrm{~N}_{2} \cdot \mathrm{C}_{2} \mathrm{~F}_{6} \mathrm{NO}_{4} \mathrm{~S}_{2}$ & $\mathrm{C}_{8} \mathrm{H}_{8} \mathrm{Br}_{5} \mathrm{~N}_{2} \cdot \mathrm{F}_{6} \mathrm{P}$ & $\mathrm{C}_{8} \mathrm{H}_{8} \mathrm{Br}_{5} \mathrm{~N}_{2} \cdot \mathrm{Br}$ \\
\hline$M_{\mathrm{r}}$ & 342.83 & 446.69 & 444.68 & 518.88 & 516.86 & 638.02 & 676.68 & 611.62 \\
\hline Crystal size $/ \mathrm{mm}^{3}$ & $0.48 \times 0.08 \times 0.08$ & $0.28 \times 0.24 \times 0.20$ & $0.27 \times 0.24 \times 0.17$ & $0.32 \times 0.20 \times 0.02$ & $0.16 \times 0.12 \times 0.01$ & $0.24 \times 0.24 \times 0.02$ & $0.28 \times 0.20 \times 0.08$ & $0.32 \times 0.08 \times 0.08$ \\
\hline Crystal system & Orthorhombic & Tetragonal & Tetragonal & Monoclinic & Triclinic & Triclinic & Triclinic & Triclinic \\
\hline Space group & $P b c 2_{1}$ & $I 4_{1} / a$ & $I 4_{1} / a$ & $P 2_{1} / n$ & $P \overline{1}$ & $P \overline{1}$ & $P \overline{1}$ & $P \overline{1}$ \\
\hline$a / \AA$ & $7.1109(2)$ & $23.6138(3)$ & $23.4674(4)$ & $7.5434(3)$ & $8.2368(5)$ & $7.5438(4)$ & $7.6729(4)$ & $7.3200(7)$ \\
\hline$b / \AA$ & $7.8014(2)$ & $23.6138(3)$ & $23.4674(4)$ & $15.5493(7)$ & $13.4522(8)$ & $8.6311(5)$ & $7.8858(5)$ & $11.5867(12)$ \\
\hline$c / \AA$ & $15.6397(5)$ & $18.8371(4)$ & $18.6531(4)$ & $12.7552(4)$ & $13.6605(6)$ & $15.9716(7)$ & $15.8383(7)$ & $18.1972(16)$ \\
\hline$\alpha /^{\circ}$ & 90 & 90 & 90 & 90 & $92.476(4)$ & $75.020(4)$ & $90.001(4)$ & $87.611(8)$ \\
\hline$\beta /^{\circ}$ & 90 & 90 & 90 & $90.198(3)$ & $100.965(4)$ & $87.083(4)$ & $88.104(4)$ & $81.121(8)$ \\
\hline$\gamma /{ }^{\circ}$ & 90 & 90 & 90 & 90 & $92.884(5)$ & $66.580(5)$ & $62.169(8)$ & $86.375(8)$ \\
\hline$V / \AA^{3}$ & $867.61(4)$ & $10503.8(3)$ & $10272.6(3)$ & $1496.11(10)$ & $1481.96(14)$ & $920.25(8)$ & $846.88(9)$ & $1521.0(3)$ \\
\hline$Z$ & 4 & 32 & 32 & 4 & 4 & 2 & 2 & 4 \\
\hline$D_{\mathrm{x}} / \mathrm{g} \cdot \mathrm{cm}^{-3}$ & 2.63 & 2.26 & 2.30 & 2.30 & 2.32 & 2.30 & 2.65 & 2.67 \\
\hline$\mu / \mathrm{mm}^{-1}$ & 13.88 & 9.24 & 9.45 & 8.25 & 11.70 & 6.88 & 12.01 & 15.81 \\
\hline$F(000) / \mathrm{e}$ & 632 & 6720 & 6656 & 984 & 976 & 608 & 628 & 1120 \\
\hline \multirow[t]{2}{*}{$\sin \theta_{\max } / \lambda$} & 0.60 & 0.60 & 0.60 & 0.60 & 0.60 & 0.60 & 0.67 & 0.60 \\
\hline & $-8 \leq h \leq 8$ & $-28 \leq h \leq 26$ & $-28 \leq h \leq 24$ & $-9 \leq h \leq 8$ & $-9 \leq h \leq 9$ & $-9 \leq h \leq 6$ & $-9 \leq h \leq 10$ & $-8 \leq h \leq 8$ \\
\hline \multirow[t]{2}{*}{$h, k, l$ range } & $-9 \leq k \leq 9$ & $-28 \leq k \leq 28$ & $-28 \leq k \leq 23$ & $-18 \leq k \leq 15$ & $-16 \leq k \leq 15$ & $-10 \leq k \leq 9$ & $-10 \leq k \leq 10$ & $-12 \leq k \leq 13$ \\
\hline & $-18 \leq l \leq 15$ & $-14 \leq l \leq 22$ & $-22 \leq l \leq 21$ & $-15 \leq l \leq 15$ & $-16 \leq l \leq 12$ & $-19 \leq l \leq 19$ & $-20 \leq l \leq 14$ & $-21 \leq l \leq 18$ \\
\hline Absorption correction & Multi-scan & Multi-scan & Analytical & Multi-scan & Multi-scan & Gaussian & Multi-scan & Multi-scan \\
\hline Measured reflections & 4789 & 32072 & 31973 & 9203 & 16144 & 5550 & 5619 & 12598 \\
\hline Independent reflections & 1276 & 4811 & 4684 & 2715 & 5289 & 3329 & 3506 & 5551 \\
\hline$\left(R_{\text {int }}\right)$ & $(0.031)$ & $(0.052)$ & $(0.068)$ & $(0.066)$ & $(0.038)$ & $(0.040)$ & $(0.023)$ & $(0.052)$ \\
\hline
\end{tabular}


Table 1. Cont.

\begin{tabular}{|c|c|c|c|c|c|c|c|c|}
\hline $\begin{array}{l}\text { Observed reflections } \\
\qquad[I \geq 2 \sigma(I)]\end{array}$ & 1243 & 3786 & 3838 & 2078 & 4748 & 2302 & 2920 & 4184 \\
\hline Restraints/parameters & $1 / 104$ & $10 / 315$ & $14 / 315$ & $15 / 188$ & $0 / 363$ & $1 / 243$ & $7 / 204$ & $0 / 291$ \\
\hline$R_{1} / \mathrm{w} R_{2}[I \geq 2 \sigma(I)]$ & $0.019 / 0.042$ & $0.043 / 0.097$ & $0.044,0.103$ & $0.055 / 0.121$ & $0.039 / 0.102$ & $0.039 / 0.091$ & $0.043 / 0.102$ & $0.040 / 0.062$ \\
\hline$R_{1} / \mathrm{w} R_{2}$ (all data) & $0.021 / 0.043$ & $0.060 / 0.105$ & $0.057,0.110$ & 0.0810 .138 & $0.043 / 0.106$ & $0.061 / 0.095$ & $0.057 / 0.110$ & $0.065 / 0.071$ \\
\hline Goodness of fit & 1.09 & 1.04 & 1.07 & 1.04 & 1.03 & 0.94 & 1.07 & 1.00 \\
\hline$\Delta \rho_{\max / \min } / \mathrm{e} \AA^{-3}$ & $0.53 /-0.48$ & $1.59 /-0.76$ & $1.96 /-1.03$ & $1.26 /-0.88$ & $1.82 /-0.79$ & $1.01 /-0.88$ & $1.73 /-1.49$ & $0.86 /-0.77$ \\
\hline
\end{tabular}


Table 2. Halogen bonding and hydrogen bonding in 2-9.

\begin{tabular}{|c|c|c|c|c|c|}
\hline Compound & Interaction & Distance $(d / \AA)$ & $d-\sum r_{\mathrm{vdW}}(\AA)$ & Angle $\left(^{\circ}\right)$ & Symmetry Operator \\
\hline 2 & $\mathrm{C}-\mathrm{Br} 3 \cdots \mathrm{N} 2$ & $3.089(4)$ & -0.311 & $159.8(2)$ & $1+x, y, z$ \\
\hline \multirow[t]{6}{*}{3} & $\mathrm{C}-\mathrm{Br} 11 \cdots \mathrm{F} 5$ & $2.869(5)$ & -0.451 & $166.1(2)$ & $x, y, z$ \\
\hline & $\mathrm{C}-\mathrm{Br} 31 \cdots \mathrm{F} 7$ & $2.869(4)$ & -0.451 & $168.9(2)$ & $-1 / 2+x, y, 1 / 2-z$ \\
\hline & $\mathrm{C}-\mathrm{Br} 21 \cdots \mathrm{F} 4$ & $2.906(5)$ & -0.414 & $179.5(2)$ & $3 / 4+y, 3 / 4-x,-1 / 4+z$ \\
\hline & $\mathrm{C}-\mathrm{Br} 12 \cdots \mathrm{F} 3$ & $3.041(6)$ & -0.279 & $158.1(2)$ & $x, y, z$ \\
\hline & $\mathrm{C}-\mathrm{Br} 22 \cdots \mathrm{F} 8$ & $3.090(5)$ & -0.230 & $172.2(2)$ & $5 / 4+y, 5 / 4-x, 1 / 4+z$ \\
\hline & $\mathrm{C}-\mathrm{Br} 32 \cdots \mathrm{F} 3$ & $3.137(6)$ & -0.183 & 147.4(2) & $5 / 4+y, 5 / 4-x, 1 / 4+z$ \\
\hline \multirow[t]{7}{*}{4} & $\mathrm{C}-\mathrm{Br} 22 \cdots \mathrm{F} 2$ & $2.822(5)$ & -0.498 & $167.8(2)$ & $1 / 4+y, 1 / 4-x, 1 / 4+z$ \\
\hline & $\mathrm{C}-\mathrm{Br} 12 \cdots \mathrm{F} 5$ & $2.826(6)$ & -0.494 & $166.1(2)$ & $-1 / 2+x, y, 3 / 2-z$ \\
\hline & $\mathrm{C}-\mathrm{Br} 32 \cdots \mathrm{F} 6$ & $2.944(5)$ & -0.376 & $165.3(2)$ & $x, y, z$ \\
\hline & $\mathrm{C}-\mathrm{Br} 11 \cdots \mathrm{F} 3$ & $2.972(7)$ & -0.348 & $161.7(2)$ & $1-x,-y, 1-z$ \\
\hline & $\mathrm{C}-\mathrm{Br} 21 \cdots \mathrm{F} 7$ & $3.094(5)$ & -0.226 & $167.2(2)$ & $1 / 4-y,-1 / 4+x,-1 / 4+z$ \\
\hline & $\mathrm{C}-\mathrm{Br} 32 \cdots \mathrm{F} 7$ & $3.141(7)$ & -0.179 & $151.6(2)$ & $x, y, z$ \\
\hline & $\mathrm{C}-\mathrm{Br} 31 \cdots \mathrm{F} 3$ & $3.244(7)$ & -0.076 & $152.2(2)$ & $1 / 4+y, 3 / 4-x, 3 / 4-z$ \\
\hline \multirow[t]{2}{*}{5} & $\mathrm{C}-\mathrm{Br} 2 \cdots \mathrm{F} 3 \mathrm{~A}$ & $2.927(10)$ & -0.393 & $161.5(4)$ & $1-x,-y, 2-z$ \\
\hline & $\mathrm{C}-\mathrm{Br} 3 \cdots \mathrm{F} 2$ & $2.989(5)$ & -0.331 & $160.0(3)$ & $3 / 2+x, 1 / 2-y, 1 / 2+z$ \\
\hline \multirow[t]{6}{*}{6} & $\mathrm{C}-\mathrm{Br} 21 \cdots \mathrm{F} 13$ & $3.010(3)$ & -0.310 & $160.9(1)$ & $1-x, 1-y, 1-z$ \\
\hline & $\mathrm{C}-\mathrm{Br} 31 \cdots \mathrm{F} 22$ & $3.060(4)$ & -0.260 & 161.1(2) & $x, y, z$ \\
\hline & $\mathrm{C}-\mathrm{Br} 22 \cdots \mathrm{F} 14$ & $3.084(3)$ & -0.236 & $158.9(1)$ & $x, y, z$ \\
\hline & $\mathrm{C}-\mathrm{Br} 11 \cdots \mathrm{F} 23$ & $3.157(5)$ & -0.163 & $154.9(2)$ & $x, y, 1+z$ \\
\hline & $\mathrm{C}-\mathrm{Br} 12 \cdots \mathrm{F} 21$ & $3.209(6)$ & -0.111 & $127.0(2)$ & $1-x,-y,-z$ \\
\hline & $\mathrm{C}-\mathrm{Br} 32 \cdots \mathrm{F} 15$ & $3.255(4)$ & -0.065 & $171.0(1)$ & $1-x, 1-y, 1-z$ \\
\hline \multirow[t]{4}{*}{7} & $\mathrm{C}-\mathrm{Br} 3 \cdots \mathrm{O} 3$ & $2.943(4)$ & -0.427 & $167.1(2)$ & $-1+x, 1+y, z$ \\
\hline & $\mathrm{C}-\mathrm{Br} 2 \cdots \mathrm{O} 3$ & $3.201(3)$ & -0.169 & $152.9(2)$ & $1-x, 1-y, 1-z$ \\
\hline & $\mathrm{C}-\mathrm{H} 6 \cdots \mathrm{O} 1$ & $2.32(5)$ & -0.402 & $160(5)$ & $-x, 1-y, 2-z$ \\
\hline & $\mathrm{C}-\mathrm{F} 3 \cdots \mathrm{F} 3$ & $2.700(7)$ & -0.240 & $163.7(4)$ & $1-x, 1-y, 2-z$ \\
\hline \multirow[t]{5}{*}{8} & $\mathrm{C}-\mathrm{Br} 3 \cdots \mathrm{F} 2$ & $3.017(6)$ & -0.303 & $173.6(2)$ & $x, 1+y, z$ \\
\hline & $\mathrm{C}-\mathrm{Br} 5 \cdots \mathrm{Br} 5$ & $3.517(1)$ & -0.183 & $143.6(2)$ & $3-x,-y, 2-z$ \\
\hline & $\mathrm{C}-\mathrm{Br} 2 \cdots \mathrm{Br} 2$ & $3.575(1)$ & -0.125 & $129.6(2)$ & $2-x, 1-y, 1-z$ \\
\hline & $\mathrm{C}-\mathrm{H} 6 \cdots \mathrm{F} 6$ & $2.38(3)$ & -0.290 & $164(4)$ & $x, y, z$ \\
\hline & $\mathrm{C}-\mathrm{H} 6 \cdots \mathrm{F} 2$ & $2.50(6)$ & -0.174 & $140(4)$ & $x, y, z$ \\
\hline \multirow[t]{8}{*}{9} & $\mathrm{C}-\mathrm{Br} 1 \cdots \mathrm{Br} 6$ & $3.032(1)$ & -0.668 & $177.7(2)$ & $1-x,-y,-z$ \\
\hline & $\mathrm{C}-\mathrm{Br} 7 \cdots \mathrm{Br} 12$ & $3.092(1)$ & -0.608 & $177.6(2)$ & $1-x, 1-y, 1-z$ \\
\hline & $\mathrm{C}-\mathrm{Br} 8 \cdots \mathrm{Br} 6$ & $3.201(1)$ & -0.499 & $176.6(2)$ & $1+x, y, z$ \\
\hline & $\mathrm{C}-\mathrm{Br} 9 \cdots \mathrm{Br} 12$ & $3.230(1)$ & -0.470 & $175.2(2)$ & $1-x,-y, 1-z$ \\
\hline & $\mathrm{C}-\mathrm{Br} 3 \cdots \mathrm{Br} 12$ & $3.291(1)$ & -0.409 & $175.6(2)$ & $x, y, z$ \\
\hline & $\mathrm{C}-\mathrm{Br} 4 \cdots \mathrm{Br} 4$ & $3.474(1)$ & -0.226 & $152.9(2)$ & $2-x,-1-y,-z$ \\
\hline & $\mathrm{C}-\mathrm{H} 8 \cdots \mathrm{Br} 6$ & $2.756(1)$ & -0.294 & $148.3(4)$ & $x, y, z$ \\
\hline & $\mathrm{C}-\mathrm{H} 16 \cdots \mathrm{Br} 12$ & $2.812(1)$ & -0.238 & $155.1(4)$ & $x, y, z$ \\
\hline
\end{tabular}

Lately, attractive anion $\cdots \pi$ interactions have been recognized as supramolecular forces between anions and electron-deficient heterocyclic ring system [33,34]. We indeed observed interactions of the tetrafluoroborate, hexafluorophosphate, and triflimide anions with the tribromoimidazolium system. The cut-off for anion $\cdots \pi$ interactions has not been clearly established [33]. We judged such an 
interaction as existing when at least three interactions with the atoms of a five-membered ring shorter than the sum of van der Waals (vdW) radii were found, as in compounds 3-5 and 7 (Table 3).

Table 3. Anion $\cdots \pi$ interactions in $3,4,5$ and 7.

\begin{tabular}{|c|c|c|c|c|}
\hline Compound & Interaction & Distance $(d / \AA)$ & $d-\sum r_{\mathrm{vdW}}(\AA)$ & Symmetry Operator \\
\hline \multirow[t]{6}{*}{3} & $\mathrm{C} 11 \cdots \mathrm{F} 5$ & $2.900(7)$ & -0.270 & $3 / 4+y, 5 / 4-x, 1 / 4-z$ \\
\hline & $\mathrm{C} 21 \cdots \mathrm{F} 5$ & $3.084(7)$ & -0.086 & $3 / 4+y, 5 / 4-x, 1 / 4-z$ \\
\hline & $\mathrm{N} 21 \cdots \mathrm{F} 5$ & $2.935(6)$ & -0.085 & $3 / 4+y, 5 / 4-x, 1 / 4-z$ \\
\hline & $\mathrm{C} 31 \cdots \mathrm{F} 5$ & $3.137(7)$ & -0.033 & $3 / 4+y, 5 / 4-x, 1 / 4-z$ \\
\hline & $\mathrm{N} 11 \cdots \mathrm{F} 5$ & $3.025(7)$ & +0.005 & $3 / 4+y, 5 / 4-x, 1 / 4-z$ \\
\hline & centroid $\cdots F 5$ & 2.790 & & \\
\hline \multirow[t]{6}{*}{4} & $\mathrm{C} 32 \cdots \mathrm{F} 5$ & $3.162(9)$ & -0.008 & $1 / 4-y,-1 / 4+x,-1 / 4+z$ \\
\hline & $\mathrm{N} 22 \cdots \mathrm{F} 5$ & $2.957(7)$ & -0.063 & $1 / 4-y,-1 / 4+x,-1 / 4+z$ \\
\hline & $\mathrm{C} 12 \cdots \mathrm{F} 5$ & $2.940(8)$ & -0.230 & $1 / 4-y,-1 / 4+x,-1 / 4+z$ \\
\hline & $\mathrm{C} 22 \cdots \mathrm{F} 5$ & $3.109(8)$ & -0.061 & $1 / 4-y,-1 / 4+x,-1 / 4+z$ \\
\hline & $\mathrm{N} 12 \cdots \mathrm{F} 5$ & $3.073(8)$ & +0.053 & $1 / 4-y,-1 / 4+x,-1 / 4+z$ \\
\hline & centroid $\cdots$ F5 & 2.824 & & \\
\hline \multirow[t]{6}{*}{5} & $\mathrm{C} 3 \cdots \mathrm{F} 4 \mathrm{~B}$ & $3.10(1)$ & -0.068 & $1 / 2+x, 1 / 2-y, 1 / 2+z$ \\
\hline & $\mathrm{C} 1 \cdots \mathrm{F} 4 \mathrm{~B}$ & $3.11(1)$ & -0.055 & $1 / 2+x, 1 / 2-y, 1 / 2+z$ \\
\hline & $\mathrm{C} 2 \cdots \mathrm{F} 4 \mathrm{~B}$ & $3.13(1)$ & -0.044 & $1 / 2+x, 1 / 2-y, 1 / 2+z$ \\
\hline & $\mathrm{N} 1 \cdots \mathrm{F} 4 \mathrm{~B}$ & $3.10(1)$ & +0.080 & $1 / 2+x, 1 / 2-y, 1 / 2+z$ \\
\hline & $\mathrm{N} 2 \cdots \mathrm{F} 4 \mathrm{~B}$ & $3.16(1)$ & +0.140 & $1 / 2+x, 1 / 2-y, 1 / 2+z$ \\
\hline & centroid $\cdots$ F4B & 2.901 & & \\
\hline \multirow[t]{6}{*}{7} & $\mathrm{C} 3 \cdots \mathrm{O} 2$ & $2.901(6)$ & -0.319 & $x, y, z$ \\
\hline & $\mathrm{C} 2 \cdots \mathrm{O} 2$ & $3.054(7)$ & -0.166 & $x, y, z$ \\
\hline & $\mathrm{N} 1 \cdots \mathrm{O} 2$ & $3.041(7)$ & -0.029 & $x, y, z$ \\
\hline & $\mathrm{C} 1 \cdots \mathrm{O} 2$ & $3.255(8)$ & +0.035 & $x, y, z$ \\
\hline & $\mathrm{N} 2 \cdots \mathrm{O} 2$ & $3.278(7)$ & +0.208 & $x, y, z$ \\
\hline & centroid $\cdots \mathrm{O} 2$ & 2.887 & & \\
\hline
\end{tabular}

Table 4. Percent contributions of selected interactions relative to the whole Hirshfeld surface. Independent cations are termed A and B.

\begin{tabular}{|c|c|c|c|c|c|c|c|c|c|c|c|c|}
\hline \multirow[t]{2}{*}{ Interaction } & \multicolumn{12}{|c|}{ Compound } \\
\hline & 2 & $3 \mathrm{~A}$ & $3 B$ & $4 \mathrm{~A}$ & $4 \mathrm{~B}$ & 5 & $6 \mathrm{~A}$ & $6 B$ & 7 & 8 & $9 \mathrm{~A}$ & $9 B$ \\
\hline $\mathrm{Br} \cdots \mathrm{Br}$ & 12.0 & 9.4 & 9.5 & 11.1 & 10.1 & 7.3 & 5.8 & 5.2 & 5.6 & 19.0 & 22.4 & 22.7 \\
\hline $\mathrm{Br} \cdots \mathrm{H} / \mathrm{H} \cdots \mathrm{Br}$ & 36.3 & 24.4 & 27.0 & 23.1 & 21.8 & 22.3 & 20.5 & 18.5 & 13.5 & 29.2 & 54.7 & 55.4 \\
\hline $\mathrm{Br} \cdots \mathrm{C} / \mathrm{C} \cdots \mathrm{Br}$ & 18.8 & 1.6 & 0.9 & 1.8 & 4.2 & 1.1 & 3.2 & 3.5 & 4.0 & 5.9 & 8.9 & 6.9 \\
\hline $\mathrm{Br} \cdots \mathrm{N} / \mathrm{N} \cdots \mathrm{Br}$ & 10.5 & 0.2 & 0.2 & 0.2 & 0.4 & 0 & 0 & 0 & 0.2 & 0 & 1.3 & 1.3 \\
\hline $\mathrm{Br} \cdots \mathrm{O}$ & - & - & - & - & - & - & - & - & 8.9 & - & - & - \\
\hline $\mathrm{Br} \cdots \mathrm{F}$ & - & 13.3 & 13.2 & 16.5 & 13.7 & 13.8 & 17.5 & 15.8 & 14.4 & 13.7 & - & - \\
\hline $\mathrm{C} \cdots \mathrm{H} / \mathrm{H} \cdots \mathrm{C}$ & 12.9 & 4.0 & 5.1 & 16.6 & 9.9 & 1.7 & 15.2 & 12.4 & 0.7 & 0 & 3.2 & 4.5 \\
\hline $\mathrm{C} \cdots \mathrm{O}$ & - & - & - & - & - & - & - & - & 6.3 & - & - & - \\
\hline$C \cdots F$ & - & 4.9 & 4.5 & 7.6 & 9.2 & 5.1 & 5.3 & 5.8 & 6.8 & 4.4 & - & - \\
\hline $\mathrm{H} \cdots \mathrm{F}$ & - & 20.9 & 16.8 & 7.6 & 16.3 & 26.6 & 18.7 & 24.7 & 17.2 & 19.6 & - & - \\
\hline$H \cdots H$ & 1.1 & 19.1 & 20.6 & 5.5 & 11.8 & 20.4 & 11.4 & 11.7 & 4.2 & 6.5 & 9.6 & 9.1 \\
\hline $\mathrm{H} \cdots \mathrm{O}$ & - & - & - & - & - & - & - & - & 11.9 & - & - & - \\
\hline
\end{tabular}


A few imidazolium tetrafluoroborates which also exhibit this type of interaction with short F*-centroid distances have been located in the CSD [35-37], although not described as such by the respective authors. Likewise, examples of $\mathrm{PF}_{6} \cdots \pi$ [38-40] and $\mathrm{S}=\mathrm{O} \cdots \pi[30,41,42]$ interactions in imidazolium hexafluorophosphates, triflimides, and triflates should be mentioned.

Commonly accepted van der Waals radii $[43,44]$ were used in this work, although the radii of anionic species may be considered to be larger [33]. Finally, Hirshfeld surface analysis [45-48] was performed to obtain quantitative insight into the cation-anion interactions (Table 4).

\subsection{2,4,5-Tribromo-1-(prop-2-ynyl)imidazole (2)}

The imidazole molecules are arranged in chains in the $\left[\begin{array}{lll}1 & 0 & 0\end{array}\right]$ direction by short $\mathrm{Br} \cdots \mathrm{N}$ interactions, as shown in Figure 2. Distance and angle of this directed interaction are in the typical range. Being the only neutral molecule in this study, electrostatic $\mathrm{N} \cdots \mathrm{H}$ interactions are found by Hirshfeld surface analysis, whereas the ionic compounds show zero interactions of this kind. On the other hand, $\mathrm{H} \cdots \mathrm{H}$ interactions are negligible in 2 compared to the salt structures 3-9.

Figure 2. Chains of molecules of 2 in the direction of the crystallographic $a$ axis.

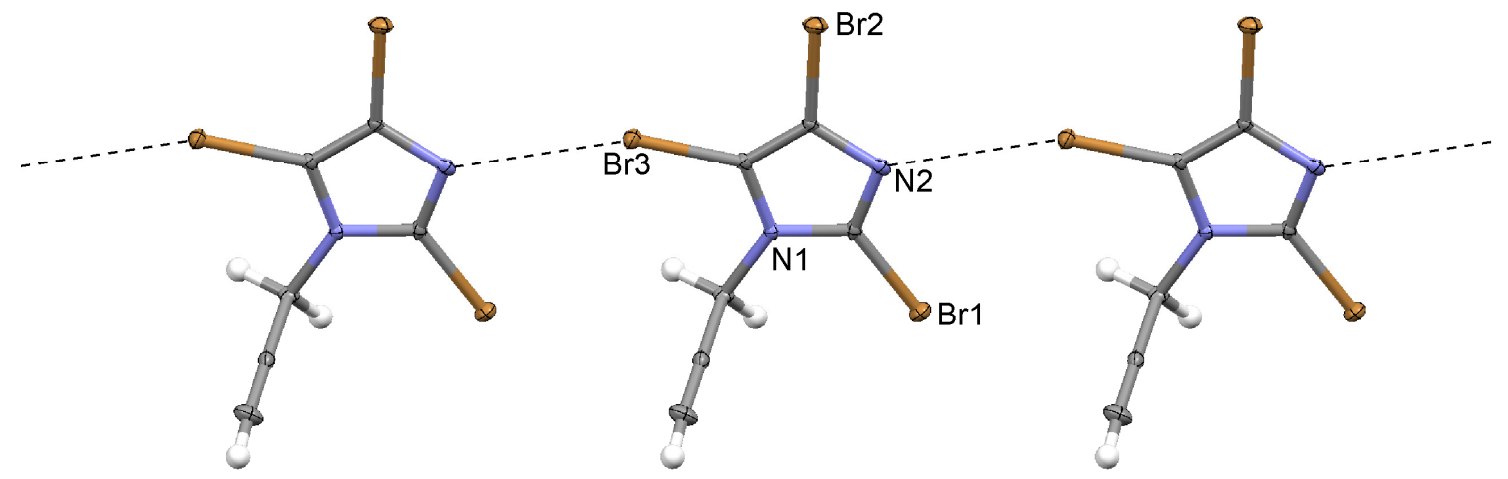

\subsection{2,4,5-Tribromo-3-methyl-1-(prop-2-enyl)imidazolium Tetrafluoroborate (3)}

Two independent ion pairs are found in the asymmetric unit. Short $\mathrm{Br} \cdots \mathrm{F}$ contacts are clearly detected between the tribromoimidazolium cations and the tetrafluoroborate anions (Figure 3). The $\mathrm{C}-\mathrm{Br} \cdots \mathrm{F}$ angles are nearly linear, exceptions are probably due to packing effects. There are indisputable interactions of the anion with the aromatic $\pi$ system observed, with a short anion $\cdots$ centroid distance. Evidently, the anion is located on top of the aromatic ring, fixed by four contacts shorter than the sum of van der Waals radii (Table 3). These weak interactions can be overridden by packing effects [49], and it has been remarked that it is still not possible to predict anion $\cdots \pi$ interactions [49]. Thus, it is not surprising that the $\pi$-system of the second cation does not exhibit perceptible interactions with an anion. 
Figure 3. (a) Typical Br..F interactions; and (b) the anion $\cdots \pi$ interactions in the propenyl imidazolium tetrafluoroborate 3. Only one of the two independent cations is shown. The other one exhibits very similar Br...F contacts.

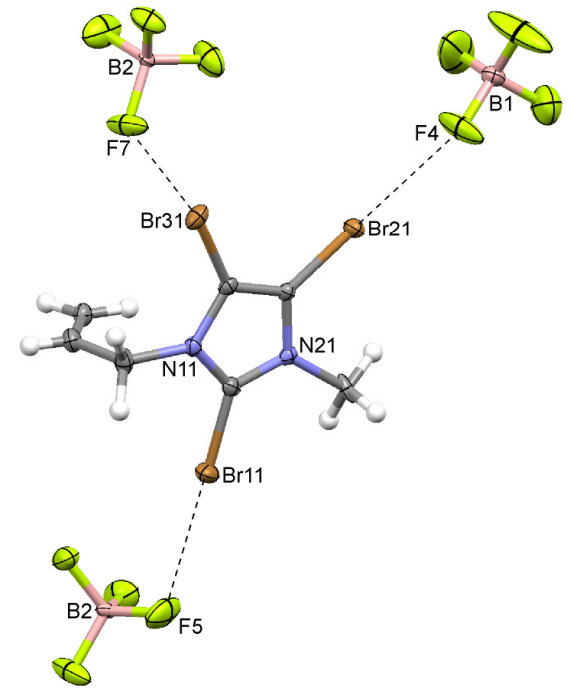

(a)

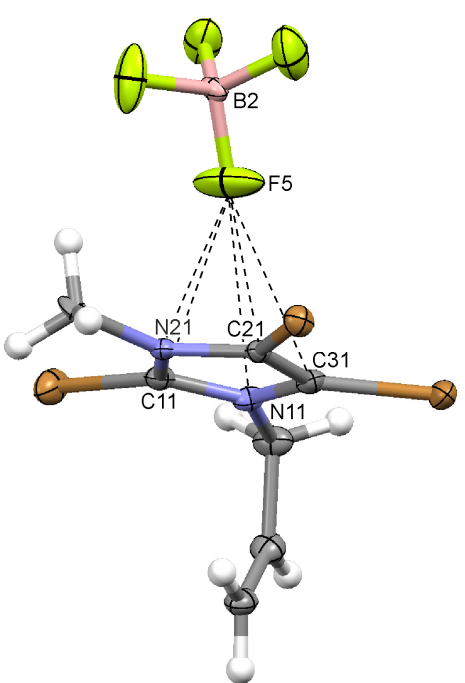

(b)

\subsection{2,4,5-Tribromo-3-methyl-1-(prop-2-ynyl)imidazolium Tetrafluoroborate (4)}

The unit cell is very similar to that of the previous compound 3. Again, two ion pairs are in the asymmetric unit. The $\mathrm{Br} \cdots \mathrm{F}$ contacts, with angles between 152 and $168^{\circ}$ (Table 2) are slightly different, one bromine atom exhibiting a bifurcated $\mathrm{Br} \cdots \mathrm{F}$ interaction (Figure $4 \mathrm{a}$ ). The $\pi$-system of one imidazolium cation is involved in four short contacts with a tetrafluoroborate anion (Table 3). In contrast to 3 , a surprisingly high contribution of $\mathrm{C} \cdots \mathrm{H}$ interactions is revealed by Hirshfeld surface analysis which, everything else being equal, can only be attributed to the propynyl substituent.

Figure 4. (a) Typical $\mathrm{Br} \cdots \mathrm{F}$ interactions; and (b) the anion $\cdots \pi$ interactions in the propenyl imidazolium tetrafluoroborate 4. Only one of the two independent cations is shown. The

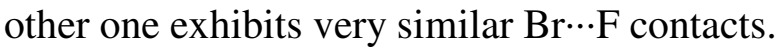

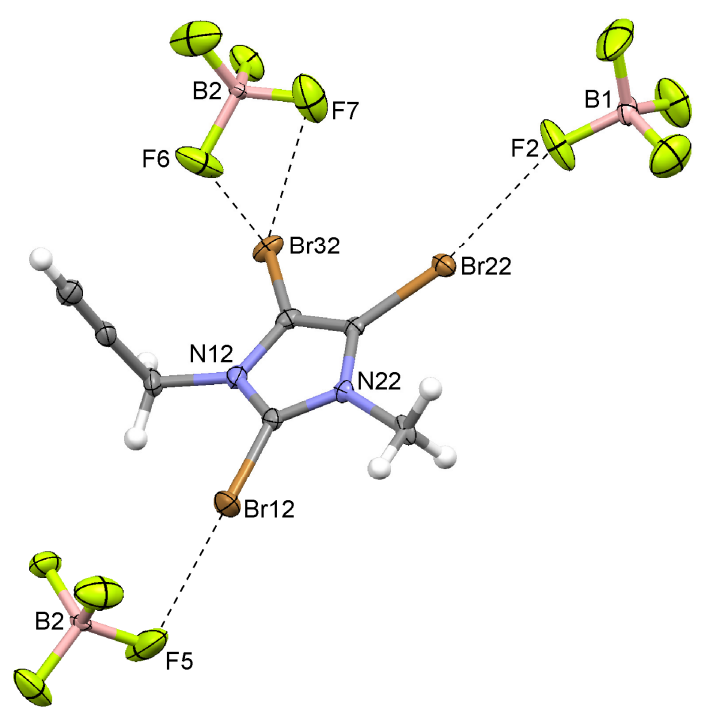

(a)

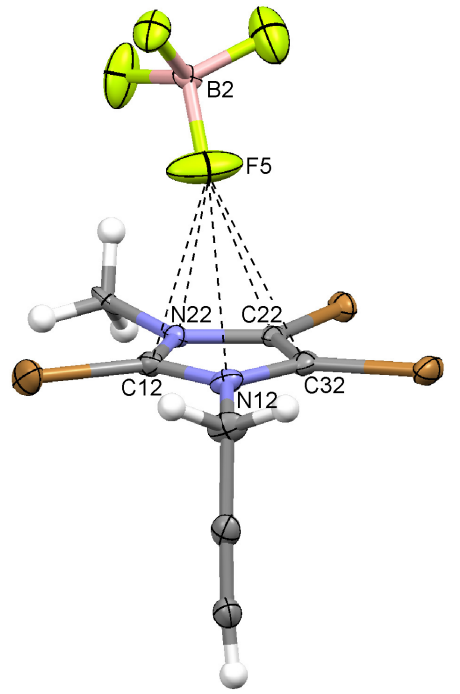

(b) 


\subsection{2,4,5-Tribromo-3-ethyl-1-(prop-2-enyl)imidazolium Hexafluorophosphate (5)}

In this structure, the two alkyl substituents of the imidazolium cation adopt an anti conformation. The pronounced prolate shape of the thermal ellipsoids of some of the fluorine atoms of the $\mathrm{PF}_{6}$ anion indicated the presence of a disorder that was modeled by introducing split positions (A and B with occupancy factors of 0.50) for the F1, F3 and F4 atoms, which were refined isotropically. Since no temperature dependent measurements were performed the question remains whether the disorder is static or dynamic. Two short $\mathrm{Br} \cdots \mathrm{F}$ contacts with $\mathrm{C}-\mathrm{Br} \cdots \mathrm{F}$ angles around $160^{\circ}$ are observed. A skewed anion $\cdots \pi$ interaction (Figure 5a) is found with a short F*..centroid distance (Table 3). Obviously, the anion is not located exactly over the center of the ring, only three contacts shorter than the sum of van der Waals radii are found in this case. The anion is interacting predominantly with the carbon atoms of the heterocyclic ring system.

Figure 5. Interionic interactions in the hexafluorophosphates of (a) the propenyl imidazolium salt $5(\mathrm{Br} \cdots \mathrm{F}$ and anion $\cdots \pi)$ and $(\mathbf{b})$ the propynyl imidazolium salt $6(\mathrm{Br} \cdots \mathrm{F})$. Only one of the two independent cations in 6 is shown.

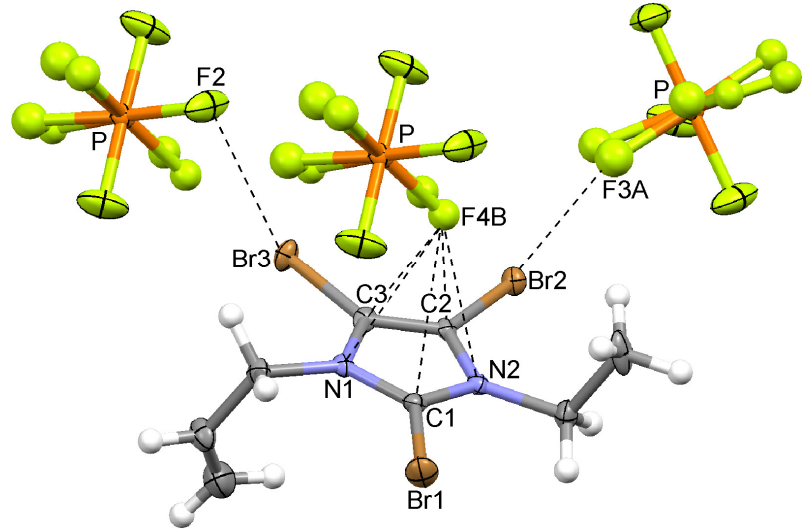

(a)

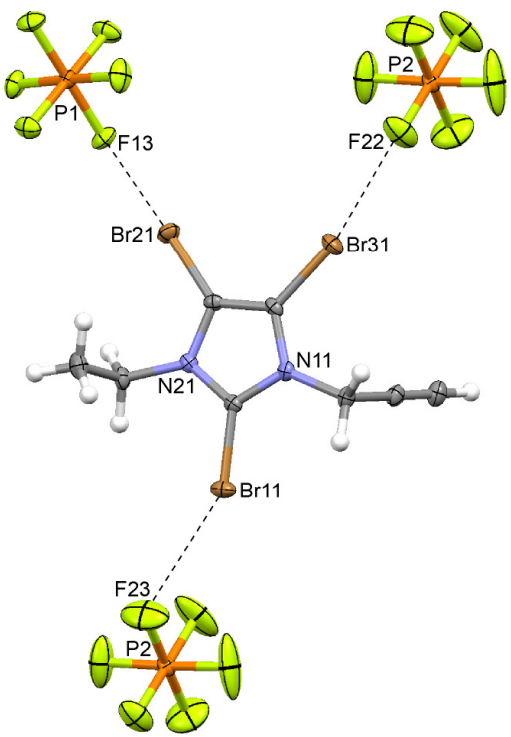

(b)

\subsection{2,4,5-Tribromo-3-ethyl-1-(prop-2-ynyl)imidazolium Hexafluorophosphate (6)}

Two ion pairs are located in the asymmetric unit. Again, the two alkyl substituents adopt the anti conformation. In this instance, no anion $\cdots \pi$ interaction is detected, but the typical $\mathrm{Br} \cdots \mathrm{F}$ contacts (Figure $5 b$ ) are found in both ion pairs. The $\mathrm{C}-\mathrm{Br} \cdots \mathrm{F}$ angles range from 155 to $171^{\circ}$ (Table 2 ) which is the typical angular preference [28]. One interaction $(\mathrm{C}-\mathrm{Br} 12 \cdots \mathrm{F} 21)$ exhibits a suspiciously small angle. However, this contact is three percent shorter than the sum of van der Waals radii and cannot be ignored. Once again, a surprisingly high contribution of $\mathrm{C} \cdots \mathrm{H}$ interactions is revealed by Hirshfeld surface analysis. 


\subsection{2,4,5-Tribromo-3-methyl-1-(prop-2-ynyl)imidazolium Triflimide (7)}

The triflimide ion adopts the anti conformation $\left(\mathrm{C}-\mathrm{S} \cdots \mathrm{S}-\mathrm{C}\right.$ torsion angle of $\left.170.6^{\circ}\right)$; this conformation is preferred in metal-free triflimide structures [50]. The angle $\mathrm{C}-\mathrm{C} \equiv \mathrm{C}$ is found to be 175.8 . A "classic" $\mathrm{C}_{\mathrm{sp}}-\mathrm{H} \cdots \mathrm{O}$ hydrogen bond between $\mathrm{H} 6$ and $\mathrm{O} 1$ is observed, thus forming a cyclic dimer (Figure 6). Interestingly, in this structure no $\mathrm{Br} \cdots \mathrm{Br}$ or $\mathrm{Br} \cdots \mathrm{F}$ interactions are found, but $\mathrm{Br} \cdots \mathrm{O}$ contacts to the sulfonyl group, as noticed earlier in related structures $[17,51,52]$, and a $F \cdots F$ contact across a symmetry center. However, an anion $\cdots \pi$ interaction is observed. This time one partially negatively charged oxygen atom of a sulfonyl group is involved in three contacts shorter than the sum of van der Waals radii. Again, the interacting atom of the anion is shifted from the center of the $\pi$ system and is located over the rim of the heterocycle, exhibiting short contacts with N1, C2, and C3 of the imidazolium ring.

Figure 6. Classic $\mathrm{C}-\mathrm{H} \cdots \mathrm{O}$ hydrogen bonds forming a cyclic dimer and anion $\cdots \pi$ interaction in the propynyl imidazolium triflimide 7.

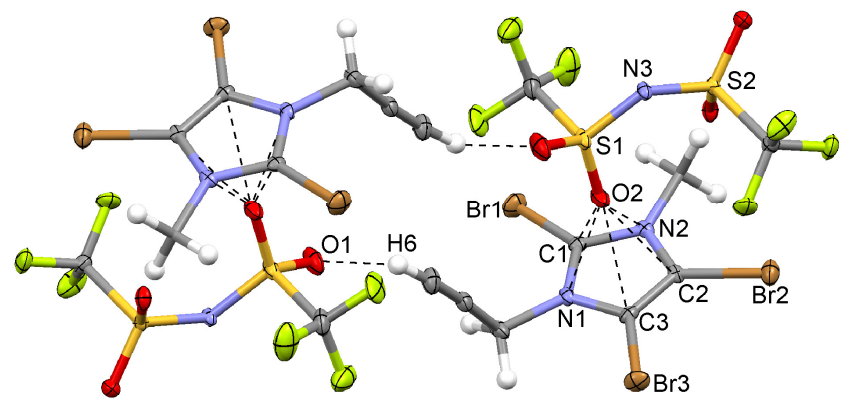

\subsection{2,4,5-Tribromo-1-(2,3-dibromoprop-2-enyl)-3-ethylimidazolium Hexafluorophosphate (8)}

As before, there are almost linear $\mathrm{Br} \cdots \mathrm{F}$ contacts between the ions. The structure also exhibits $\mathrm{Br} 2 \cdots \mathrm{Br} 2$ interactions in the ring plane, forming layers which are connected by $\mathrm{Br} 5 \cdots \mathrm{Br} 5$ contacts to give a three-dimensional network (Figure 7 ). The $\mathrm{Br} \cdots \mathrm{Br}$ contacts are both across a symmetry center, deviate from linearity due to packing (Table 2), and are also found prominently in the Hirshfeld surface analysis (Table 4). The allylic $\mathrm{C}-\mathrm{H} \cdots \mathrm{F}$ interactions are also detected in the Hirshfeld analysis.

Figure 7. The halogen $\cdots$ halogen interactions in 2,4,5-tribromo-1-(2,3-dibromoprop-2-enyl)imidazolium hexafluorophosphate (8).

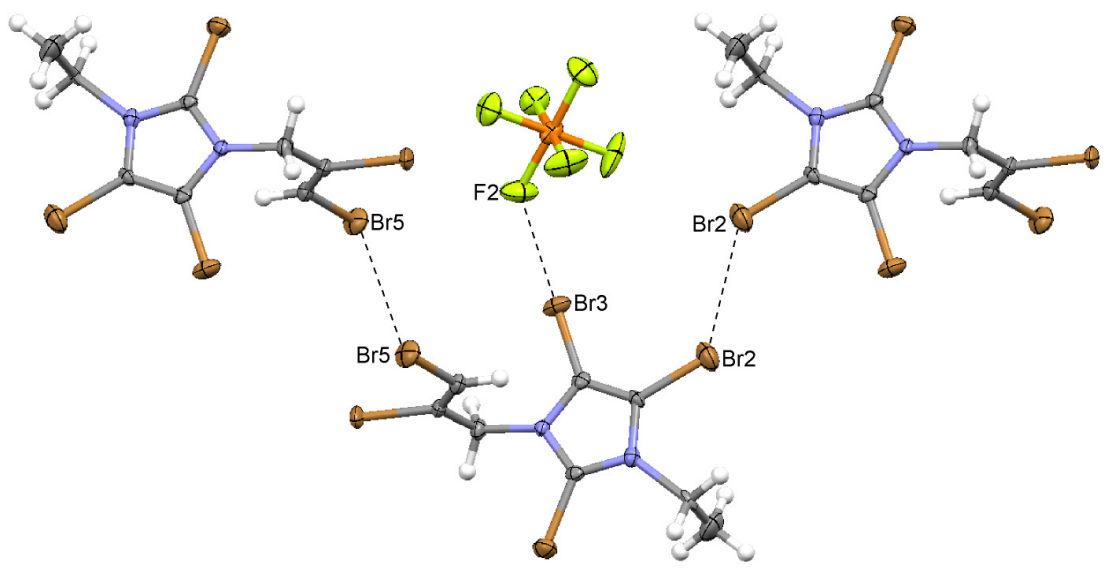




\subsection{2,4,5-Tribromo-1-(2,3-dibromoprop-2-enyl)-3-ethylimidazolium Bromide (9)}

Two independent ion pairs are located in the asymmetric unit. The presence of the brominated side chain results in an increased number of $\mathrm{Br} \cdots \mathrm{Br}$ contacts such as short $\mathrm{Br} 4 \cdots \mathrm{Br} 4$ and weak $\mathrm{Br} 1 \cdots \mathrm{Br} 1$ and $\mathrm{Br} 9 \cdots \mathrm{Br} 9$ contacts across a symmetry center. Strong bromine $\cdots$ bromide contacts exist in the crystal which are significantly shorter than the sum of van der Waals radii, even without taking into account the fact that bromide has a larger van der Waals radius than covalently bound bromine [33]. The $\mathrm{C}-\mathrm{Br} \cdots \mathrm{Br}^{-}$angles are close to $180^{\circ}$, indicating linearity of the $\mathrm{X}$-bonds. The coordination around the two independent bromide ions is shown in Figure 8. It is not unexpected that, due to the brominated side chain, contacts involving $\mathrm{Br}$ atoms are quite dominant in the Hirshfeld surface analysis. According to this analysis, $\mathrm{C}-\mathrm{H} \cdots \mathrm{Br}$ contacts by far represent the majority of interactions, obviously due to the relatively strong $\mathrm{C}_{\mathrm{sp}^{2}} 2-\mathrm{H} \cdots \mathrm{Br}^{-}$interactions, followed by $\mathrm{Br} \cdots \mathrm{Br}$ contacts. Some examples of similar situations are found in the Cambridge Structural Database [53-56].

Figure 8. Bromine $\cdots$ Bromide and hydrogen $\cdots$ bromide coordination of the two independent bromide ions (a) Br6 and (b) Br12 in the structure of 2,4,5-tribromo-(2,3-dibromoprop-2enyl)-3-ethylimidazolium bromide (9).

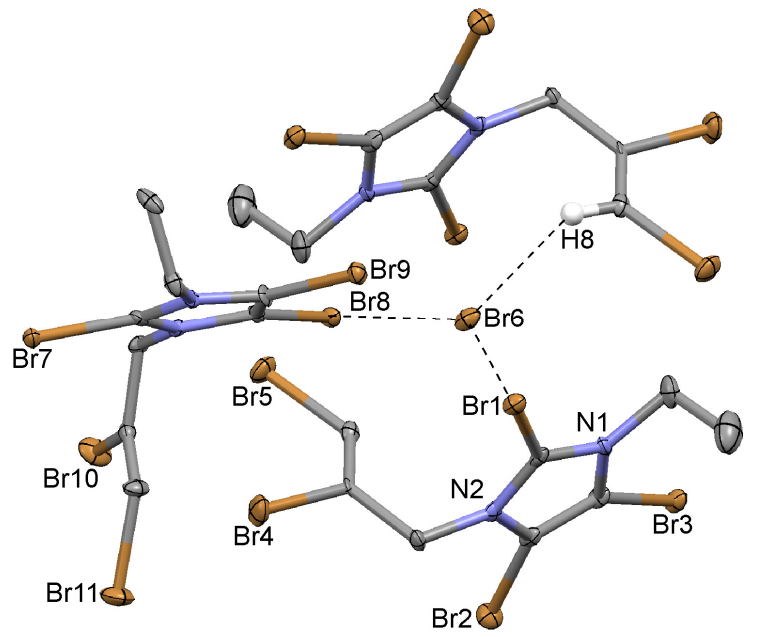

(a)

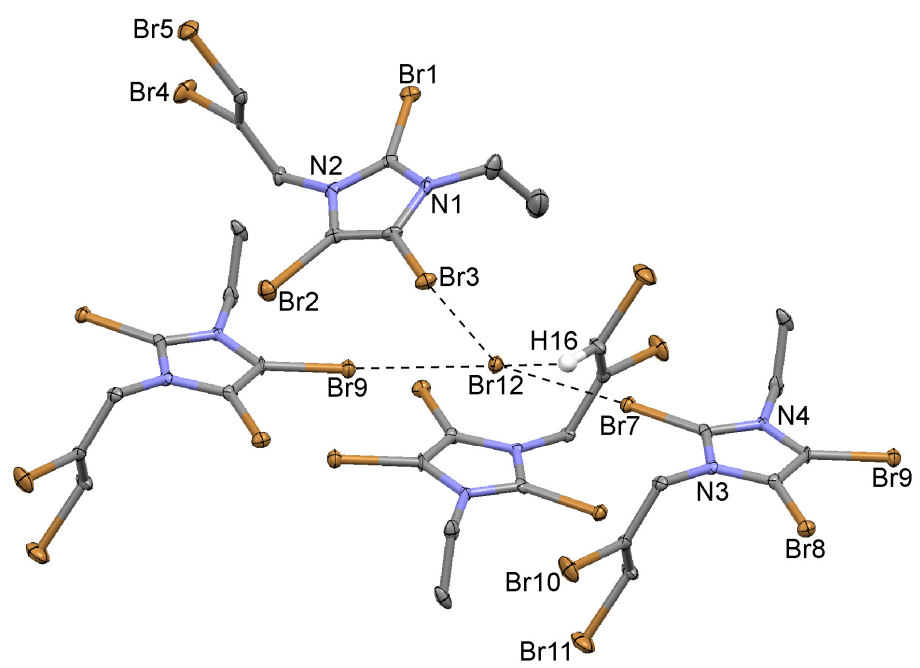

(b) 


\section{Experimental Section}

Chemicals and solvents were purchased from Sigma-Aldrich and used as received. 2,4,5-Tribromo-1-(prop-2-enyl)imidazole (1) [CARN 31255-41-1] and 2,4,5-tribromo-1-(prop-2-ynyl) imidazole (2) [CARN 27442-77-9] were prepared according to published procedures [12,13,57].

\subsection{Data of 2,4,5-Tribromo-1-(Prop-2-Ynyl)Imidazole (2)}

m.p. $123{ }^{\circ} \mathrm{C}$. IR (neat): v 3288 (m), 2129 (w), 1494 (m), 1433 (m), 1410 (m), 1380 (m), 1335 (m), $1214(\mathrm{~m}), 1192(\mathrm{~m}), 1121(\mathrm{~m}), 985(\mathrm{~m}), 937(\mathrm{~m}), 758(\mathrm{~m}), 682(\mathrm{~s}), 651(\mathrm{~s}) \cdot \mathrm{cm}^{-1} \cdot{ }^{13} \mathrm{C} \mathrm{NMR}$ (DMSO-d 6 , 75 MHz): $\delta 37.7,76.4,76.8,105.9,116.0,118.9$ ppm. Single crystals were obtained from $\mathrm{MeOH}$.

\subsection{General Procedure for the Alkylation of 1-Alkylimidazoles (3-6)}

To a solution of trimethyloxonium tetrafluoroborate or triethyloxonium hexafluorophosphate (16 mmol) in anhydrous $\mathrm{CH}_{2} \mathrm{Cl}_{2}(5 \mathrm{~mL})$ the respective 2,4,5-tribromo-1-alkylimidazole (1.0 eq.) was added and stirred overnight at room temperature. $\mathrm{Et}_{2} \mathrm{O}$ was added, and the resulting colorless solid was filtered and dried under reduced pressure. Single crystals were obtained from $\mathrm{MeOH}$.

2,4,5-Tribromo-3-methyl-1-(prop-2-enyl)imidazolium tetrafluoroborate (3): m.p. $179{ }^{\circ} \mathrm{C}$. IR (neat): $v 1553(\mathrm{w}), 1501$ (w), 1049 (s), 1035 (s), 946 (w), 669 (w) $\cdot \mathrm{cm}^{-1} \cdot{ }^{13} \mathrm{C}$ NMR (DMSO-d $\left.6,75 \mathrm{MHz}\right): \delta$ $37.8,52.4,110.8,112.5,118.9,124.5,129.1 \mathrm{ppm}$.

2,4,5-Tribromo-3-methyl-1-(prop-2-ynyl)imidazolium tetrafluoroborate (4): m.p. $203{ }^{\circ} \mathrm{C}$. IR (neat): v $2135(\mathrm{w}), 1554(\mathrm{w}), 1498(\mathrm{w}), 1050(\mathrm{~s}), 1035(\mathrm{~s}), 816(\mathrm{w}), 679(\mathrm{w}), 652(\mathrm{w}) \cdot \mathrm{cm}^{-1}$.

2,4,5-Tribromo-3-ethyl-1-(prop-2-enyl)imidazolium hexafluorophosphate (5): m.p. $228{ }^{\circ} \mathrm{C}$ (dec). IR (neat): $v 1496(\mathrm{w}), 1122(\mathrm{w}), 936(\mathrm{w}), 831(\mathrm{~s}), 669(\mathrm{w}) \cdot \mathrm{cm}^{-1}$.

2,4,5-Tribromo-3-ethyl-1-(prop-2-ynyl)imidazolium hexafluorophosphate (6): m.p. $232{ }^{\circ} \mathrm{C}$ (dec). IR (neat): v 2135 (w), 1559 (w), $1494(w), 1118$ (m), 1051 (s), $833(\mathrm{~s}), 710(\mathrm{~s}) \cdot \mathrm{cm}^{-1}$.

\subsection{2,4,5-Tribromo-3-methyl-1-(prop-2-ynyl)imidazolium Triflimide (7)}

A solution of 2,4,5-tribromo-3-methyl-1-(prop-2-ynyl)imidazolium tetrafluoroborate (4) and lithium triflimide (1.05 eq.) in $\mathrm{MeOH}$ was stirred for $18 \mathrm{~h}$. After evaporation of the solvent, the residual solid was suspended in $\mathrm{H}_{2} \mathrm{O}$. The mixture was extracted twice with $\mathrm{CH}_{2} \mathrm{Cl}_{2}$. The organic phase was washed three times with $\mathrm{H}_{2} \mathrm{O}$ and dried under reduced pressure to give a colorless solid. m.p. $122{ }^{\circ} \mathrm{C}$. IR (neat): v 2135 (w), 1556 (w), 1500 (w), 1351 (s), 1333 (m), 1190 (s), 1178 (s), 1137 (s), 1116 (m), 1046 (s), 1033 (s), 959 (w), 819 (w), 794 (w), 743 (w), 694 (w), $613(\mathrm{~s}) \cdot \mathrm{cm}^{-1}$. Single crystals were obtained from $\mathrm{MeOH}$.

\subsection{2,4,5-Tribromo-1-(2,3-dibromoprop-2-enyl)-3-ethylimidazolium Hexafluorophosphate (8)}

Bromine (1.0 eq.) was added to an ice-cooled suspension of 6 in $\mathrm{CH}_{2} \mathrm{Cl}_{2}$. The mixture was stirred at room temperature for $18 \mathrm{~h}$, and the colorless precipitate was filtered, washed with $\mathrm{CH}_{2} \mathrm{Cl}_{2}$, and dried 
under reduced pressure. m.p. $206^{\circ} \mathrm{C}$. IR (neat): $v 837(\mathrm{~s}), 673(\mathrm{w}) \cdot \mathrm{cm}^{-1}$. Single crystals were obtained from $\mathrm{MeOH}$.

\subsection{2,4,5-Tribromo-1-(2,3-dibromoprop-2-enyl)-3-ethylimidazolium Bromide (9)}

Crystals of this minor byproduct were spotted in the major product 8 .

\subsection{X-ray Crystal Structure Determination}

Intensity data were recorded with an Oxford Diffraction Gemini-R Ultra diffractometer using Mo- $K \alpha$ radiation at $T=173(2) \mathrm{K}$. For $6, \mathrm{Cu}-\mathrm{K \alpha}$ radiation was used. Experimental details are summarized in Table 1. Structure solution and refinement was performed with the programs SIR2002 (direct methods) [58] and SHELXL-97 [59]. A Flack parameter of 0.03(2) was obtained for the non-centrosymmetric structure of 2 . The crystals of 8 were subject to non-merohedral twinning which was taken into consideration during data reduction, integration and refinement. Visualization of the structures and measurements of distances and angles was performed with the program Mercury [60]. CCDC reference numbers: 881951-881958. These data can be obtained free of charge from The Cambridge Crystallographic Data Centre.

\section{Conclusions}

The crystal structures of eight $N$-alkylated 2,4,5-tribromoimidazole compounds were determined. Halogen interactions and anion $\cdots \pi$ interactions were detected. Hirshfeld surface analysis (Figure 9) yielded quantitative information about these interactions. These results are supposed to further our understanding of halogen interactions in the solid state.

Figure 9. (a) Normalized Hirshfeld surface of the cation in 5 and associated fingerprint plots highlighting specific interactions; (b) $\mathrm{Br} \cdots \mathrm{Br}$; (c) $\mathrm{Br} \cdots \mathrm{H}$ (reciprocal interactions

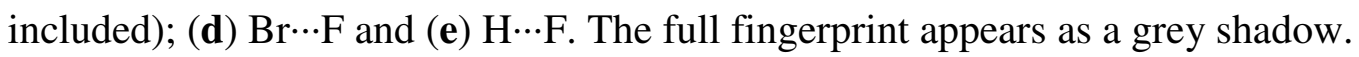

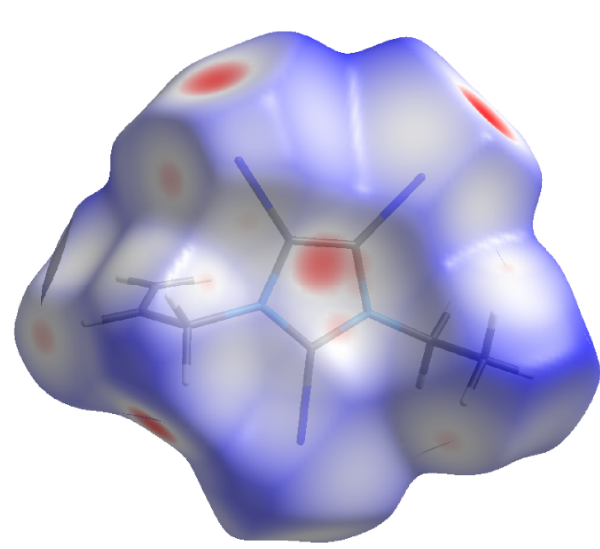

(a)

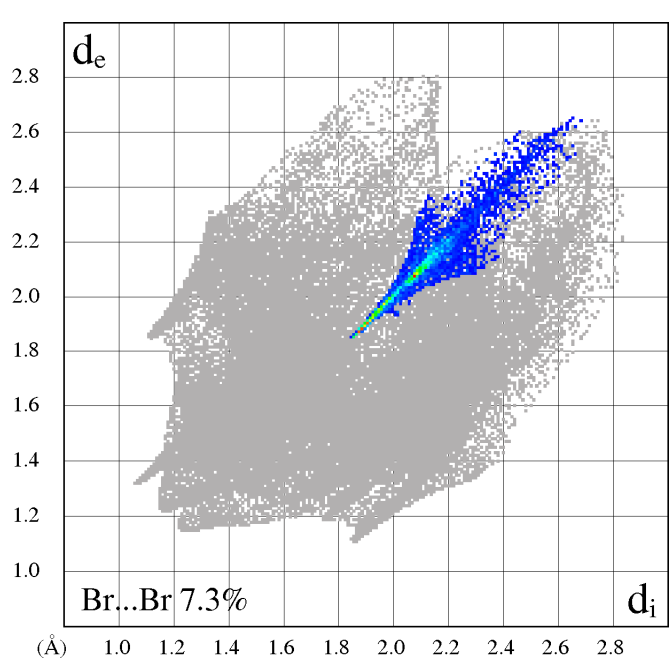

(b) 
Figure 9. Cont.

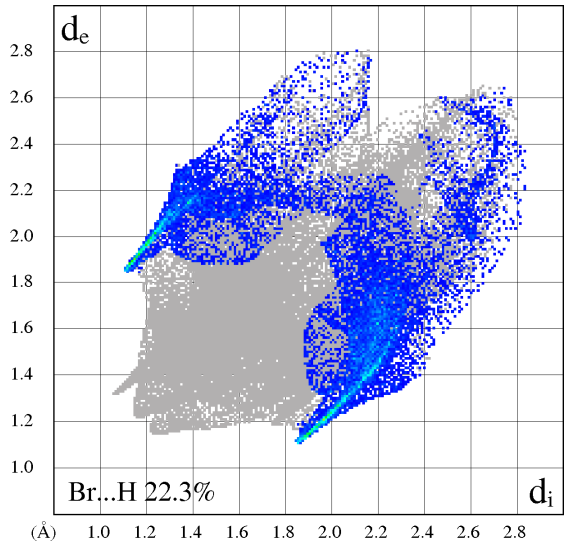

(c)

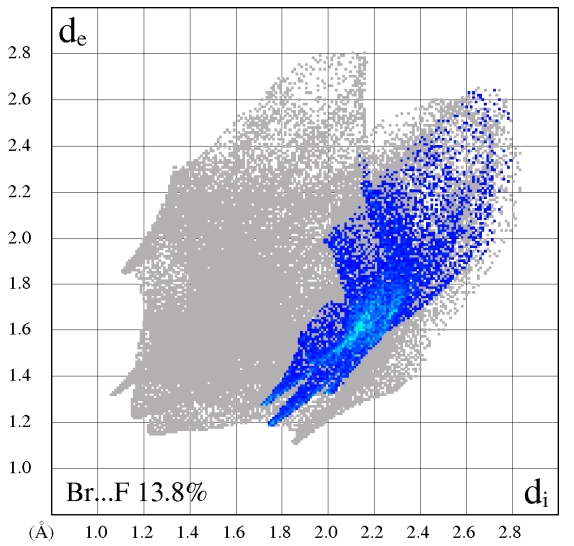

(d)

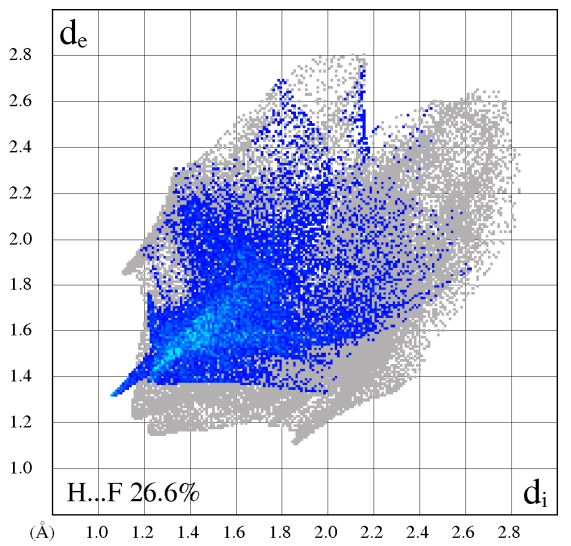

(e)

\section{Acknowledgments}

Financial support was provided by the Austrian government, the provinces of Lower Austria, Upper Austria and Carinthia as well as by the Lenzing AG.

\section{References}

1. Wyss, G. Zur Kenntnis des Glyoxalins. Chem. Ber. 1877, 10, 1365-1375.

2. Balaban, I.E.; Pyman, F.L. Bromo-Derivatives of Glyoxaline. J. Chem. Soc. Trans. 1922, 121, 947-958.

3. Chaudhuri, M.K.; Khan, A.T.; Patel, B.K.; Dey, D.; Kharmawophlang, W.; Lakshmiprabha, T.R.; Mandal, G.C. An environmentally benign synthesis of organic ammonium tribromides (OATB) and bromination of selected organic substrates by tetrabutylammonium tribromide (TBATB). Tetrahedron Lett. 1998, 39, 8163-8166.

4. Bahnous, M.; Mouats, C.; Fort, Y.; Gros, P.C. Convenient multi-gram scale synthesis of polybrominated imidazoles building blocks. Tetrahedron Lett. 2006, 47, 1949-1951.

5. Muathen, H.A. 1,8-Diazabicyclo[5.4.0]undec-7-ene hydrobromide perbromide: A new mild stable brominating agent for aromatic compounds. J. Org. Chem. 1992, 57, 2740-2741.

6. Nath, J.; Chaudhuri, M.K. Boric acid catalyzed bromination of a variety of organic substrates: An eco-friendly and practical protocol. Green Chem. Lett. Rev. 2008, 1, 223-230.

7. Stensiö, K.-E.; Wahlberg, K.; Wahren, R. Synthesis of brominated imidazoles. Acta Chem. Scand. 1973, 27, 2179-2183.

8. Benkendorff, K.; Pillai, R.; Bremner, J.B. 2,4,5-Tribromo-1H-imidazole in the egg masses of three muricid molluscs. Nat. Prod. Res. 2004, 18, 427-431.

9. Schulze, H.; Klein, H.P. Fire-retardant polyurethane composition. US Patent 4,032,484, 28 June 1977.

10. Ye, C.; Shreeve, J.M. Syntheses of very dense halogenated liquids. J. Org. Chem. 2004, 69, 6511-6513. 
11. Yano, T.; Tomioka, H.; Takada, Y.; Takeda, H.; Hirata, N. New trihaloimidazole derivatives possessing a high insecticidal activity against the pyrethroid-resistant colony of the German cockroach, Blattella germanica (Dictyoptera: Blattellidae). Appl. Ent. Zool. 1991, 26, 469-475.

12. Martin, H.; Pissiotas, G. Ectoparasiticidal 1-alkynyl-2,4,5-trihaloimidazoles. German Patent DE 1950991A, 1970.

13. Pissiotas, G. Acaricidal 2,4,5-trihaloimidazoles. German Patent DE 2031400 A, 1971.

14. Draber, W.; Falbe, J.F.; Buechel, K.H.; Korte, F.W.A.G.K. Plant Growth Control. U.S. Patent 3,501,286, 17 March 1970.

15. Noland, W.E.; Cole, K.P.; Britton, D. 4,5-Dibromo-1-methyl-1H-imidazole. Acta Crystallogr. 2003, E59, o458-0460.

16. Mukai, T.; Nishikawa, K. Halogen-Bonded and hydrogen-bonded network structures in crystals of 1-propyl- and 1-butyl-4,5-dibromo-3-methylimidazolium bromides. Chem. Lett. 2009, 38, 402-403.

17. Mukai, T.; Nishikawa, K. Syntheses and crystal structures of two ionic liquids with halogen-bonding groups: 4,5-dibromo- and 4,5-diiodo-1-butyl-3-methylimidazolium trifluoromethane-sulfonates. Solid State Sci. 2010, 12, 783-788.

18. Serpell, C.J.; Kilah, N.L.; Costa, P.J.; Felix, V.; Beer, P.D. Halogen bond anion templated assembly of an imidazolium pseudorotaxane. Angew. Chem. Int. Ed. 2010, 49, 5322-5326.

19. Blackman, A.G.; Buckingham, D.A.; Clark, C.R.; Simpson, J. Bromination of imidazole complexes of pentaammine-cobalt(III). Synthesis, structure and reactivity. J. Chem. Soc. Dalton Trans. 1991, 3031-3041.

20. Hassel, O. Structural aspects of interatomic charge-transfer bonding. Science 1970, 170, 497-502.

21. Awwadi, F.F.; Willett, R.D.; Peterson, K.A.; Twamley, B. The nature of halogen $\cdots$ halogen synthons: Crystallographic and theoretical studies. Chem. Eur. J. 2006, 12, 8952-8960.

22. Dikundwar, A.G.; Guru Row, T.N. Evidence for the "amphoteric" nature of fluorine in halogen bonds: An instance of Cl $\cdots$ F contact. Cryst. Growth Des. 2012, 12, 1713-1716.

23. Kubicki, M. Structural phase transitions, and $\mathrm{Br} \cdots \mathrm{N}$ and $\mathrm{Br} \cdots \mathrm{Br}$ interactions in 1-phenyl-2-methyl4-nitro-5-bromoimidazole. Acta Crystallogr. 2004, B60, 333-342.

24. Valkonen, J.; Pitkanen, I.; Pajunen, A. Molecular and crystal structure and IR spectrum of 3,5-Dibromo-1,2,4-triazole. Acta Chem. Scand. 1985, A39, 711-716.

25. Ansell, G.B. Tetrazole studies. Part II. Crystal structure of 5-bromotetrazole. J. Chem. Soc. Perkin Trans. 2 1973, 2036-2038.

26. Eißmann, F.; Schindler, D.; Weber, E. X-ray crystal structures of halogen containing nucleobase derivatives in unsolvated and DMSO solvated forms. Struct. Chem. 2010, 21, 245-254.

27. Chopra, D.; Guru Row, T.N. Role of organic fluorine in crystal engineering. CrystEngComm. 2011, 13, 2175-2186.

28. D'Oria, E.; Novoa, J.J. On the hydrogen bond nature of the C-H $\cdots$ F interactions in molecular crystals. An exhaustive investigation combining a crystallographic database search and ab initio theoretical calculations. CrystEngComm 2008, 10, 423-436.

29. Cole, M.L.; Jones, C.; Junk, P.C. Studies of the reactivity of N-heterocyclic carbenes with halogen and halide sources. New J. Chem. 2002, 26, 1296-1303. 
30. Laus, G.; Schwärzler, A.; Schuster, P.; Bentivoglio, G.; Hummel, M.; Wurst, K.; Kahlenberg, V.; Lörting, T.; Schütz, J.; Peringer, P.; et al. $N, N$ '-Di(alkyloxy)imidazolium salts: New patent-free ionic liquids and NHC precatalysts. Z. Naturforsch. 2007, B62, 295-308.

31. Kuhn, N.; Abu-Rayyan, A.; Eichele, K.; Schwarz, S.; Steimann, M. Weak interionic interactions in 2-bromoimidazolium derivatives. Inorg. Chim. Acta 2004, 357, 1799-1804.

32. Sünkel, K.; Bernhartzeder, S. Coordination chemistry of perhalogenated cyclopentadienes and alkynes. XXVIII new high-yield synthesis of monobromoferrocene and simplified procedure for the synthesis of pentabromoferrocene. Molecular structures of 1,2,3-tribromoferrocene and 1,2,3,4,5-pentabromoferrocene. J. Organomet. Chem. 2011, 696, 1536-1540.

33. Estarellas, C.; Bauza, A.; Frontera, A.; Quiñonero, D.; Deya, P.M. On the directionality of anion- $\pi$ interactions. Phys. Chem. Chem. Phys. 2011, 13, 5696-5702.

34. Robertazzi, A.; Krull, F.; Knapp, E.-W.; Gamez, P. Recent advances in anion- $\pi$ interactions. CrystEngComm 2011, 13, 3293-3300.

35. Pointer, D.J.; Wilford, J.B. Crystal and molecular structure of 3,3'-thio-bis-(2-methyl-1phenylimidazo-[1,5-a]pyridinium) bistetrafluoroborate; a potent new sulphur-containing curariform agent. J. Chem. Soc. Chem. Commun. 1978, 816-817.

36. Frank, B.; Beckert, R.; Rau, S.; Görls, H. 2-Azaanthraquinones: Building blocks for new ring-fused imidazoles and their transformation into benzo[f]isoindole-4,9-diones. Z. Naturforsch. 2005, B60, 771-779.

37. Kunz, D.; Deißler, C.; Gierz, V.; Rominger, F.; Oeser, T. Reduction of dipyrido ureas via 6-alkyloxydipyrido[1,2-c;2',1'-e]imidazolium salts. Z. Naturforsch. 2010, B65, 861-872.

38. Brown, D.H.; Skelton, B.W. Nickel complexes of a bis(benzimidazolin-2-ylidene)pyridine pincer ligand with four- and five-coordinate geometries. Dalton Trans. 2011, 40, 8849-8858.

39. Laus, G.; Wurst, K.; Kahlenberg, V.; Kopacka, H.; Kreutz, C.; Schottenberger, H. N-Heterocyclic carbene (NHC) derivatives of 1,3-di(benzyloxy)imidazolium salts. Z. Naturforsch. 2010, B65, 776-782.

40. Scheele, U.J.; Dechert, S.; Meyer, F. Bridged dinucleating $N$-heterocyclic carbene ligands and their double helical mercury(II) complexes. Inorg. Chim. Acta 2006, 359, 4891-4900.

41. Weigand, J.J.; Feldmann, K.-O.; Henne, F.D. Carbene-Stabilized phosphorus(III)-centered cations $\left[\mathrm{LPX}_{2}\right]^{+}$and $\left[\mathrm{L}_{2} \mathrm{PX}\right]^{2+}\left(\mathrm{L}=\mathrm{NHC} ; \mathrm{X}=\mathrm{Cl}, \mathrm{CN}, \mathrm{N}_{3}\right)$. J. Am. Chem. Soc. 2010, 132, 16321-16323.

42. Maas, G.; Stang, P.J. Structures of dication ethers. Crystal and molecular structures of bis(1,3-dimethyl-2-imidazoliniumyl) ether ditriflate and bis[1,2-bis(dimethylamino)-3-cyclopropenyliumyl] ether ditriflate. J. Org. Chem. 1983, 48, 3038-3043.

43. Bondi, A. Van der Waals volumes and radii. J. Phys. Chem. 1964, 68, 441-451.

44. Rowland, R.S.; Taylor, R. Intermolecular nonbonded contact distances in organic crystal structures: Comparison with distances expected from van der Waals radii. J. Phys. Chem. 1996, 100, 7384-7391.

45. Spackman, M.A.; Jayatilaka, D. Hirshfeld surface analysis. CrystEngComm 2009, 11, 19-32.

46. McKinnon, J.J.; Jayatilaka, D.; Spackman, M.A. Towards quantitative analysis of intermolecular interactions with Hirshfeld surfaces. Chem. Commun. 2007, 3814-3816. 
47. Spackman, M.A.; McKinnon, J.J.; Jayatilaka, D. Electrostatic potentials mapped on Hirshfeld surfaces provide direct insight into intermolecular interactions in crystals. Cryst. Eng. Comm. 2008, 10, 377-388.

48. Dean, P.M.; Pringle, J.M.; Forsyth, C.M.; Scott, J.L.; MacFarlane, D.R. Interactions in bisamide ionic liquids-insights from a Hirshfeld surface analysis of their crystalline states. New J. Chem. 2008, 32, 2121-2126.

49. Albrecht, M.; Müller, M.; Mergel, O.; Rissanen, K.; Valkonen, A. CH-Directed anion- $\pi$ interactions in the crystals of pentafluorobenzyl-substituted ammonium and pyridinium salts. Chem. Eur. J. 2010, 16, 5062-5069.

50. Laus, G.; Hummel, M.; Többens, D.M.; Gelbrich, T.; Kahlenberg, V.; Wurst, K.; Griesser, U.J.; Schottenberger, $H$. The 1:1 and 1:2 salts of 1,4-diazabicyclo[2.2.2]octane and bis(trifluoro-methylsulfonyl)amine: Thermal behaviour and polymorphism. CrystEngComm 2011, 13, 5439-5446.

51. Lin, B.-L.; Kang, P.; Stack, T.D.P. Unexpected $\mathrm{C}_{\text {carbene }} \mathrm{X}(\mathrm{X}: \mathrm{I}, \mathrm{Br}, \mathrm{Cl})$ reductive elimination from $\mathrm{N}$-heterocyclic carbene copper halide complexes under oxidative conditions. Organometallics 2010, 29, 3683-3685.

52. Klapötke, T.M.; Sproll, S.M. Nitrogen-Rich polymers based on 5-bromo-1-vinyl-1H-tetrazole. Eur. J. Org. Chem. 2010, 1169-1175.

53. Linninger, C.S.; Herdtweck, E.; Hoffmann, S.D.; Herrmann, W.A.; Kühn, F.E. A new palladium(II) complex of a functionalized $N$-heterocyclic carbene: Synthesis, characterization and application in Suzuki-Miyaura cross-coupling reactions. J. Mol. Struct. 2008, 890, 192-197.

54. Domasevitch, K.V.; Boldog, I. Polar hydrogen-bonded organic chains in 4,4'-bipyrazolium bromide and perchlorate monohydrates. Acta Cryst. 2005, C61, o373-0376.

55. Peters, K.; Peters, E.M.; Reinhardt, R.; Quast, H. Crystal structure of (1R*,7S*,9S*,15R*)-2,6, 10,14-tetraazatricyclo[13.1.0.0 $\left.0^{7,9}\right]$ hexadeca-2,4,10,12-tetraene bis(hydrobromide). Z. Krist. New Cryst. Struct. 1998, 213, 609-610.

56. Gelders, Y.G.; De Ranter, C.J.; Van Rooijen-Reiss, C. 7,8-Didehydro-4,5-epoxy-17(2-propenyl)morphinan-3,6-diol hydrobromide [nalorphine hydrobromide]. Cryst. Struct. Commun. 1979, 8, 995-1003.

57. Seley, K.L.; Januszczyk, P.; Hagos, A.; Zhang, L.; Dransfield, D.T. Synthesis and antitumor activity of thieno-separated tricyclic purines. J. Med. Chem. 2000, 43, 4877-4883.

58. Burla, M.C.; Carrozzini, B.; Cascarano, G.L.; Giacovazzo, C.; Polidori, G. More power for direct methods: SIR2002. Z. Kristallogr. 2002, 217, 629-635.

59. Sheldrick, G.M. A short history of SHELX. Acta Crystallogr. 2008, A64, 112-122.

60. Macrae, C.F.; Edgington, P.R.; McCabe, P.; Pidcock, E.; Shields, G.P.; Taylor, R.; Towler, M.; Van de Streek, J. Mercury: Visualization and analysis of crystal structures. J. Appl. Cryst. 2006, 39, 453-457.

(C) 2012 by the authors; licensee MDPI, Basel, Switzerland. This article is an open access article distributed under the terms and conditions of the Creative Commons Attribution license (http://creativecommons.org/licenses/by/3.0/). 